\title{
Innovation through Propagation: Using Technology to Enhance Learning and Propagation
}

\section{Dr. Milo Koretsky, Oregon State University}

Milo Koretsky is a Professor of Chemical Engineering at Oregon State University. He received his B.S. and M.S. degrees from UC San Diego and his Ph.D. from UC Berkeley, all in Chemical Engineering. He currently has research activity in areas related engineering education and is interested in integrating technology into effective educational practices and in promoting the use of higher-level cognitive skills in engineering problem solving. His research interests particularly focus on what prevents students from being able to integrate and extend the knowledge developed in specific courses in the core curriculum to the more complex, authentic problems and projects they face as professionals. Dr. Koretsky is one of the founding members of the Center for Lifelong STEM Education Research at OSU.

\section{Dr. Alejandra J. Magana, Purdue University, West Lafayette}

Alejandra Magana is an Associate Professor in the Department of Computer and Information Technology and an affiliated faculty at the School of Engineering Education at Purdue University. She holds a B.E. in Information Systems, a M.S. in Technology, both from Tec de Monterrey; and a M.S. in Educational Technology and a Ph.D. in Engineering Education from Purdue University. Her research is focused on identifying how model-based cognition in STEM can be better supported by means of expert technological and computing tools such as cyber-physical systems, visualizations and modeling and simulation tools.

\section{Dr. Larry J. Shuman, University of Pittsburgh}

Larry J. Shuman is Senior Associate Dean for Academic Affairs and Distinguished Service Professor of industrial engineering at the Swanson School of Engineering, University of Pittsburgh. His research focuses on improving the engineering education experience with an emphasis on assessment of design and problem solving, and the study of the ethical behavior of engineers and engineering managers. A former Senior Editor of the Journal of Engineering Education, Shuman is the Founding Editor of Advances in Engineering Education. He has published widely in engineering education literature, and is co-author of Engineering Ethics: Balancing Cost, Schedule and Risk - Lessons Learned from the Space Shuttle (Cambridge University Press). He received his Ph.D. from the Johns Hopkins University in Operations Research and a B.S.E.E. from the University of Cincinnati. Dr. Shuman is an ASEE Fellow. 


\section{WIP - Innovation through Propagation: Using technology to enhance learning and engagement in engineering}

\section{Introduction}

The "information age" that has ushered in the $21^{\text {st }}$ century has been built squarely on information, communications, and computational technology (ICCT). In this WIP, we explore how ICCT impacts the way that engineering is learned with the goal of establishing a research agenda for propagating the effective use of ICCT in engineering education. We seek to inform action and generate conversation amongst administrators, instructors, researchers, and students.

We can approach this goal from two broad perspectives. First, ICCT has fundamentally changed engineering practice by supporting discovery, collaboration, and innovation processes. ${ }^{1}$ In tandem, learning technologies promise to provide an unprecedented opportunity to improve instruction, provide adaptive learning, and foster increased access to education. Learning technologies consist of both tools and resources developed specifically for an educational setting and tools that have been repurposed and coupled with strategies that make them useful for learning. ${ }^{2}$ However, the engineering education community is facing the challenge to adopt approaches to technology use that are grounded in theory, and educational researchers have called for evidence for the effectiveness of the uses of technology for teaching and learning. ${ }^{3}$ In general, educators (including engineering educators) have struggled to keep pace with quickly evolving technology.

In considering the impact of technology, we may consider two distinct but related questions which lie at opposite ends of the spectrum:

1. How do we best adapt engineering programs (curricula) to prepare students to contribute effectively in a rapidly changing, technology-rich professional environment?

2. How do we corral the ever-increasing plethora of learning technologies in ways that faculty can use to effectively promote meaningful learning and equitable engagement?

In this white paper, we begin discussion with the second question while recognizing that the two questions are interdependent and we cannot answer the second without elaboration of the first. Additionally, we consider ICCT as one element in the larger ecosystem where engineering learning occurs and the issues we present strongly interact with aspects of the other two white papers in this session: (i) Learning In and Out of Class, and (ii) Pathways and Diversity.

Our premises and working scope for this paper include the following:

1. Technology is a tool that can support teaching and learning effectively (especially with increasing class sizes), but needs to be approached in conjunction with content and with pedagogical context considerations.

2. We choose to emphasize the use of technology for on-campus programs. While many of these systems can be used for learning at a distance, we are not directly addressing issues of solely distance education. While the two appear interchangeable at first blush, we believe that where and how technology is situated is foundationally related to student learning.

3. We center discussion on the undergraduate level engineering while acknowledging issues of technology in K12 and graduate education are also important. 
This work in progress paper presents three main issues that have been identified through a group of engineering education experts as the focus for systemic change for the effective integration of technology in engineering education. The three issues are:

Issue 1. Alignment of Technology with Learning: We need to intentionally align the development and use of technology with learning processes (e.g., meaning making, disciplinary practices) and with student engagement. At the same time, we must seek ways to effectively use technology to scale effective practices to mitigate ever increasing economic tensions in delivering high quality education.

Issue 2. Alignment of Technology with Faculty: We need strategies and mechanisms to address faculty pedagogical beliefs, to help develop faculty technological pedagogical content knowledge, and to connect the two.

Issue 3. Alignment of Technology with Assessment: We need to identify and implement systematic uses of process and learning data to inform formative and summative assessment, adaptive instruction, and research of learning engineering.

\section{Issue 1: Alignment of Technology with Student Learning Processes and Equitable Engagement}

We consider the following three distinct lenses which are fruitful in considering technology in engineering education: (a) cognitively oriented technology innovations, (b) technology uses in professional practice, and (c) technology-general. We believe that there is risk for cross-talk in the conversation when different interlocutors implicitly argue from different lenses. Thus, we make these lenses explicit.

Cognitively oriented technology innovations

First, we consider what Fishman and colleagues ${ }^{4}$ call cognitively oriented technology innovations (COTIs), innovations designed to foster deep thinking and meaningful learning. COTIs are learning technologies developed around instructional design that is specifically "rooted in cognitive and constructivist learning theories" (p. 45). With COTIs, "technology is employed as a tool to support teaching and learning, as opposed to the object of learning. These innovations often use technology to scaffold teaching and learning practices that would be difficult to achieve otherwise, such as making complex causal modeling accessible to students” (p. 46). In some COTIs, instruction is delivered entirely though the computer, while in others, devices form a distributed resource to promote productive face-to-face interactions and learning, such as when clickers are used to support Peer Instruction. ${ }^{5}$

\section{Technology uses in professional practice}

Second, we consider development of students' skill in technology used in engineering practice. Important technologies include disciplinary specific design tools like APSEN in chemical engineering and SPICE in electrical engineering and more general tools like high level scientific computing programming languages (e.g., MATLAB, COMSOL).

\section{Technology-general}

Third, we consider the broad impact of technology change on the instructional environment in engineering. In this aspect, there are both positive (e.g., increased resources) and negative (e.g., access to solution manuals) ways that technology impacts the learning environment. We need to understand and manage the affordances between technology as a large force in society and the 
uses in education. From this lens, it is useful to identify how technology fits into the cultures of engineering programs and the culture of higher education, with the goal of promoting systemic change towards more effective instruction.

\section{Issue 2: Strategies and Mechanisms to Address Faculty Pedagogical Beliefs and Technological Pedagogical Content Knowledge}

Higher Education has acknowledged that faculty commonly hold low digital literacy in general along with lack of pedagogical knowledge on how to effectively integrate it into their teaching practices. $^{2}$ Part of the problem relates to the lack of effective faculty training in the form of professional development. However, deeper challenges that exacerbate this issue relate to (a) faculty attitudes and pedagogical beliefs; (b) faculty development of technological pedagogical content knowledge; and (c) faculty perceptions of technology affordances.

Faculty attitudes and pedagogical beliefs

It is important to distinguish faculty knowledge (i.e., content, pedagogical, technological) from faculty attitudes and beliefs about teaching and learning and how technology enables them to translate those beliefs about teaching and learning into classroom practice. Faculty attitudes and beliefs are a vital first step toward technology acceptance and eventually integration. ${ }^{6}$ Faculty attitudes and pedagogical beliefs relate to suppositions, commitments, and ideologies that they hold about technology. 6,7

Faculty development of technological pedagogical content knowledge

Educational researchers have identified that in order to help students' improve learning with technology, it is essential for instructors to properly orchestrate the interplay among content, pedagogy, and technology. This interplay among teacher and faculty content, pedagogy and technology knowledge has been referred to as Technological Pedagogical Content Knowledge (TPCK). ${ }^{8,9}$ However, little is known about how engineering faculty develop or use this knowledge in their classrooms.

Faculty perceptions of affordances, usefulness and ease of use of technology

Factors such as perceived technology affordances and their effects in learning outcomes, along with perceived usefulness and ease of use may determine technology acceptance. ${ }^{10-12}$

\section{Issue 3: Systemic Uses of Process and Learning Data for Feedback, Assessment, Personalized Instruction and Educational Research}

Advancements in cyberinfrastructure technologies (e.g., high-performance computers, telecommunications networks, modeling and simulation, among others) along with online learning environments have resulted in learning and process data that can be now used for improving learning. ${ }^{13}$ Challenges and opportunities associated with this issue are: (a) the use process and learning data to improve learning, (b) the use process and learning data for educational research purposes, and (c) the challenges of privacy.

Learning and process data for feedback, assessment and personalized instruction As learners engage with technology, they leave a trail of ways in which they use the technology (interaction and process data) and the outcomes and the impact of using such technology (learning data). 
Learning and process data for educational research

Due to a growing interest in higher education for ways to use data for improving teaching and learning, new fields such as educational data mining and learning analytics have emerged. These fields can support the development of engineering-specific theories of learning and the characterization of different aspects of learning processes at the level of individuals, groups, and institutions.

\section{References:}

1. Madhavan, K. and Lindsay, E.D. (2014). Use of information technology in engineering education. In Johri, Aditya, and Barbara M. Olds, eds. Cambridge handbook of engineering education research. Cambridge University Press.

2. Johnson, L., Adams Becker, S., Estrada, V., Freeman, A. (2014). NMC Horizon Report: 2014 Higher Education Edition. Austin, Texas: The New Media Consortium.

3. Woolf, Beverly Park. "A roadmap for education technology." Research report. <hal-00588291> (2010) .

4. Fishman, B., Marx, R. W., Blumenfeld, P., Krajcik, J., \& Soloway, E. (2004). Creating a framework for research on systemic technology innovations. The Journal of the Learning Sciences, 13(1), 43-76.

5. Mazur, E. (1997). Peer instruction (pp. 9-18). Upper Saddle River, NJ: Prentice Hall.

6. Ertmer, P. A. (2005). Teacher pedagogical beliefs: The final frontier in our quest for technology integration? Educational technology research and development, 53(4), 25-39.

7. Ertmer, P. A., Ottenbreit-Leftwich, A. T., Sadik, O., Sendurur, E., \& Sendurur, P. (2012). Teacher beliefs and technology integration practices: A critical relationship. Computers \& Education, 59(2), 423-435.

8. Mishra, P., \& Koehler, M. (2006). Technological pedagogical content knowledge: A framework for teacher knowledge. The Teachers College Record, 108(6), 1017-1054.

9. Graham, C. R. (2011). Theoretical considerations for understanding technological pedagogical content knowledge (TPACK). Computers \& Education, 57(3), 1953-1960.

10. Nolen, S. B., Ward, C. J., Horn, I. S., Childers, S., Campbell, S. S., \& Mahna, K. (2009). Motivation Development in Novice Teachers. Contemporary Motivation Research: From Global to Local Perspectives, 265.

11. Venkatesh, V., \& Davis, F. D. (2000). A theoretical extension of the technology acceptance model: Four longitudinal field studies. Management science, 46(2), 186-204.

12. Venkatesh, V., Thong, J. Y., \& Xu, X. (2012). Consumer acceptance and use of information technology: extending the unified theory of acceptance and use of technology. MIS quarterly, 36(1), 157-178.

13. Borgman, C. L., Abelson, H., Dirks, L., Johnson, R., Koedinger, K. R., Linn, M. C., ... \& Szalay, A. (2008). Fostering learning in the networked world: The cyberlearning opportunity and challenge. A 21st century agenda for the National Science Foundation. Report of the NSF task force on cyberlearning. 